\title{
RESULTS OF RESEARCH ON THE ACTIVE SPECIES PROTECTION OF THE ROMAN SNAIL (HELIX POMATIA, LINNAEUS, 1758) USING FARMED SNAILS IN THE SECOND YEAR OF LIFE. FIRST SEASON OF THE STUDY*
}

\author{
Maciej Ligaszewski ${ }^{1 \star}$, Przemysław Pol ${ }^{1}$, Iwona Radkowska ${ }^{1}, \mathrm{Krzysztof} \mathrm{Surówka}^{2}$, Andrzej Łysak \\ ${ }^{1}$ Department of Technology, Ecology and Economics of Animal Production, \\ National Research Institute of Animal Production, 32-083 Balice n. Kraków, Poland \\ ${ }^{2}$ Department of Refrigeration and Food Concentrates, Agricultural University of Krakow, Balicka 122, \\ 10-149 Kraków, Poland \\ •Corresponding author: maciej.ligaszewski@izoo.krakow.pl
}

\begin{abstract}
The effect of three forms of active species protection in the Roman snail were studied. On the "source plot" the natural population was supported by introducing hatchlings of farmed Roman snails aged $1+$, bred from adult specimens of this population. These hatchlings (age 1+) from "source plot" population were also introduced to the following two natural plots: to the "empty plot", where the population was formed by introduction of farmed Roman snails in the second year of life $(1+)$ into a selected area which had been emptied of the natural population; to the "inhabited plot", where farmed Roman snails aged 1+, originating from breeding snails of the foreign population from a "source plot", were introduced to the local natural population. It was established that introducing Roman snails aged $1+$ and bred under farm conditions has a clearly positive influence on the age structure of the natural population in the studied plots. The rate of growth of these snails adjusted to the rate of growth of the specimens in the same age group belonging to the natural population. The farmed Roman snails grew most rapidly in the "empty plot" sown with fodder vegetation, more slowly in the "source plot" with access to appropriate herbaceous vegetation, and most slowly in the "inhabited plot". The attempt to create a naturalized population in a specially adapted "empty plot" without the natural population was successful. This was determined not only by a large number of hiding places from calcareous stones available to the Roman snails but above all by the species structure of the herb flora, which met their nutritional requirements as it contained high proportions of plants such as Brassica rapa $\times$ Brassica rapa subsp. chinensis, white clover (Trifolium repens), red clover (Trifolium pratense) and the hybrid of lucerne (Medicago $\times$ varia Martyn).
\end{abstract}

Key words: Roman snail, Helix pomatia, active protection, farmed population, natural population

In Poland the edible land snail Helix pomatia is a species of economic significance. To date there have been no attempts to apply methods of active protection of

\footnotetext{
*This work was based on the author's research financed by Ministry of Sciences and Higher Education, project No. N N304 403438.
} 
the species to the natural population. Until recently it was believed that the species is not suitable for intensive farming. This attitude has been partly negated, at least with regard to the possibility of mass production of Helix pomatia hatchlings and experiments with production of Roman snails in polycultures with the brown snail (Helix aspersa) (Ligaszewski et al., 2005, 2007). The passive protection of the natural populations of the Roman snail stems from the European Community Directive on the Conservation of Natural Habitats and of Wild Fauna and Flora (92/43/EEC). There has been no evidence that active protection of Helix pomatia could be as efficient as the methods of passive protection. Besides the important aspect of studies on the species passive protection, which focused on monitoring the natural populations in Poland (Zając, 2008), detailed ecological studies on the age structure and behaviour of the local population of the species are relatively rare (Łomnicki 1971; Pollard, 1973, 1975; Woyciechowski, 1980; Ledergerber, 1998; Andreev, 2006). Interesting research has already been undertaken on the influence of the experimental connection of adult specimens from two separate natural populations in the same area on the behaviour of the species (Woyciechowski and Łomnicki, 1977). The purpose of the study was to investigate the Roman snails populations on three natural plots, to determine the following effects of the active protection: the effect of taking individuals for reproduction and introducing juveniles to the native population; the effect of reintroducing the foreign population to a suitable habitat emptied of the natural population; the effect of reinforcing the local population by taking individuals from the same foreign population as above; the effect of taking individuals for reproduction and introducing juveniles to the native population. It was hypothesized that the growth of the farmed Roman snail hatchlings aged 1+ introduced to the natural plots will be in accordance with species biology, and the introduction will have an essential impact on the structure and numbers of the local natural populations of the Roman snail.

\section{Material and methods}

The technique used for reproduction and rearing to the age of $1+$ of Roman snail hatchlings from the population living near the "source plot" was described previously (Ligaszewski et al., 2007). In 2011, snails of the same age born in 2010, were introduced into natural plots. In 2010, the 4,000 breeding snails used for reproduction had an average shell diameter of $33.8 \mathrm{~mm}(\mathrm{SD}=1.8 \mathrm{~mm}$, $\min$. $-\max .=30.0$ $\mathrm{mm}-39.2 \mathrm{~mm})$ and body weight of $21.2 \mathrm{~g}(\mathrm{SD}=3.3 \mathrm{~g}$, $\min .-\max .=13.9-32.8 \mathrm{~g})$. The estimated total number of egg clutches was 3,124 and the number of eggs per egg clutch averaged 41.4, giving a total of around 130,000 eggs. After the incubation of eggs in special breeding trays, hatching percentage was 67.4. In this way, 87,620 early hatchings were obtained. By the autumn of 2010, around 60,000 young snails aged $0+$ were reared, with mortality of $31.5 \%$. After reproduction in greenhouses (May - mid July), breeding snails were released back to their collection site, around the "source plot". Two kilometres from that site, a surplus of 45,000 young snails aged $0+$ (out of a total of 60,000 ) were also released. The other 15,000 young snails 
aged $0+$ from the earliest greenhouse reproduction period (mid May - mid June) were put into hibernation in greenhouse enclosures. Eleven thousand snails survived greenhouse hibernation until the spring of 2011.

In mid May 2011 the farmed Roman snails aged 1+ and hibernated in the greenhouse were counted and appropriate measurements of their shells and body fresh mass were made on a random sample of snails. The shells of 9,000 snails were marked with coloured stains of quickly drying non-toxic wood varnish. Subsequently, 3,000 marked specimens were placed into each plot with three individuals per $\mathrm{m}^{-2}$. After two months, in mid July 2011, random samples of the Roman snail were collected from each plot. The samples were collected in late spring, at the end of the intensive feeding period. In the summer and often in the autumn, due to high temperature and drought, followed by cold nights, the snails of this species most often remain hidden, which makes their harvest difficult or impossible. The sampling method was that the snails were always collected by one person for a period of only 1 hour to avoid a flora and snails devastation. After separation of the snails marked year 1+ and introduced in mid May from the collected samples, a study of the age structure of the local populations was undertaken. In the natural populations of Roman snail, it was possible to differentiate three age groups for more exact identification: age group "1+", i.e. snails after their first winter hibernation; age group " $2+$ " after the second hibernation; and a group of the oldest snails aged " $3+$ and above". The age of Roman snails from natural populations was determined using the mixed method: age 1+ based on shell diameter; age 2+ according to three criteria: shell diameter, number of annual growth rings in the shell (Pollard, 1973), and incomplete shell growth, as manifested in soft and inflected lip; age 3+ and above, also based on the criteria of shell diameter and completed shell growth. Roman snails from Polish populations complete their somatic development until the autumn, mostly at age $2+$, as reflected in the shell lip turning outwards and becoming hard. The measurements of body weight and shell diameter (Ligaszewski et al., 2009) were made on the collected samples. After measuring and weighing in field conditions, the snails were immediately released back into their collection sites to avoid violating national environmental regulations. The year before, breeding Roman snails were harvested in May outside the closed season for this species. The present research was undertaken on three experimental natural plots, each having an area of $1000 \mathrm{~m}^{-2}$, located about $20 \mathrm{~km}$ from Kraków, Poland.

The results were analysed using descriptive statistics (mean, standard deviation, minimum and maximum) and analytical statistics ( $\mathrm{t}$-test and analysis of variance to determine significance of differences at $\mathrm{P} \leq 0.05$ for significant differences and $\mathrm{P} \leq 0.01$ for highly significant differences).

\section{Description of the natural conditions of the three experimental plots and structure of the Roman snail natural populations \\ The "empty plot"}

Aim of the study: to determine the effect of reintroduction into a suitable habitat. This population was created by the introduction of Helix pomatia in the second year of life (1+) from "source plot" population, raised under farm conditions, into a habitat which was earlier emptied of the natural population. 
The "empty plot" was a meadow returned to the wild state, situated on a sloping area of uncultivated lime soil land in Będkowice, which was cultivated in the past. It was an area devoid of a natural population of Helix pomatia. In 2010 this plot was equipped with hiding places for snails consisting of small piles of broken limestone arranged $80 \mathrm{~cm}$ apart in 5 rows, for which thirty tonnes of limestone were purchased, and wooden logs were placed on the ground. In 2011, before the introduction of farmed Helix pomatia, the area between the rows of stones was ploughed and sown with fodder.

Soil: rendzina - a dark, grayish-brown and humus-rich soil, whose initial stages of development are formed by weathering of soft limestone rocks;

Natural plants before ploughing and sowing with fodder (bold indicates plants that occupied more than $5 \%$ of the plot's area):

grasses: Festuca rubra L., Poa trivialis L., Echinochloa crus-galli, Agrostis capillaris L., Digitaria sanguinalis, Calamagrostis epigeios (L.) Roth;

legumes: Lotus corniculatus L., Trifolium repens L., Trifolium pratense L., Viciasepium L., Viciacracca L.;

dicotyledons: Solidago gigantea, Artemisia vulgaris L., Taraxacum officinale coll., Plantago lanceolata L., Armoracia rusticana, Ranunculus acris L., Lamium amplexicaule, Achillea millefolium L., Cirsium rivulare (Jacq.), Aegopodium podagraria L., Urticadioica L., Veronica chamaedrys L., Erigeron annus (L.) Pers, Conyza canadensis (L.) Cronquist, Polygonum aviculare L., Equisetum arvense, Rumex acetosa $\mathrm{L}$.

There were a total of 28 species in that plot.

Natural and sown plants after ploughing and sowing with fodder (bold indicates plants that occupied more than $5 \%$ of the plot's area):

grasses: Festuca rubra L., Poa pratensis L., Poa trivialis L., Lolium perenne L.;

legumes: Medicago $\times$ varia Martyn, Trifolium repens L., Trifolium pratense L., Trifolium incarnatum L.;

dicotyledons: Brassica rapa $\times$ Brassica rapa subsp. chinensis, Solidago gigantean, Achillea millefolium L., Taraxacum officinale coll., Hypericum perforatum L., Pimpinella saxifraga L., Artemisia vulgaris L., Armoracia rusticana, Phacelia tanacetifolia Benth., Sinapis alba, Ranunculus acris L., Daucus carota L. subsp. sativus (Hoffm.), Cirsium rivulare (Jacq.), Urtica dioica L., Equisetum arvense, Senecio jacobaea L., Tanacetum vulgare L.

In that plot, there were 24 species in total.

After being agriculturally enriched with fodder plants (some species of legumes and dicotyledon plants) and equipped with hiding places for snails, this plot had potentially the best biotope and trophic level conditions for Roman snails.

\section{The "inhabited plot"}

Aim of the study: to determine the effect of reinforcement of population. Active protection on an experimental plot by introducing farmed Roman snails aged 1+, originating from breeding stock of a foreign "source plot" population to the local population. 
The "inhabited plot" was a forest clearing on a slope of lime soil alongside a stream in Mydlniki-Wapiennik which had its own natural population of Helix pomatia.

Soil: half-bog soil in stream valley and rendzina soil higher on the slope;

Natural plants (bold indicates plants that occupied more than 5\% of the plot's area):

grasses: Festuca rubra L., Agrostis capillaris L., Poa trivialis L., Agrostis alba, Dactylis glomerata L., Poa annua L.;

legumes: Lotus corniculatus L., Trifolium repens L., Trifolium pratense L., Vicia cracca L.;

dicotyledons: Impatiens parviflora DC., Aegopodium podagraria L., Parthenocissus vitacea, Plantago lanceolata L., Geranium pusillum L., Chelidonium majus L., Ranunculus acris L., Achillea millefolium L., Daucus carota L., Taraxacum officinale coll., Crepis biennis L., Potentilla erecta, Urtica dioica L., Cerastium vulgatum L., Equisetum arvense, Senecio jacobaea L., Rumexa cetosa L., Oxalis acetosella L., Tanacetum vulgare L.

There were 29 species of plants in that plot.

The structure of the natural population of Roman snails was as follows: snails aged $1+-62.0 \%(\mathrm{~N}=88) ; 2+-23.9 \%(\mathrm{~N}=34) ; 3+$ and above $-14.1 \%(\mathrm{~N}=20)$ in a sample of 142 individuals.

\section{The "source plot"}

Aim of the study: to determine the effect of taking individuals for reproduction and introducing juveniles to the native population. Active protection of the natural population by introducing hatchlings of farmed Roman snails aged 1+, obtained from mature specimens originating from this population.

The "source plot" was established in Balice near Kraków in an old half-natural, forest-like park. The area around this plot was inhabited by a natural population of Roman snails from which adult specimens were taken to enable reproduction to take place in greenhouse conditions. It was from this population that all the experimentally farmed snails were introduced to the experimental plots.

Soil: rendzina;

Natural plants (bold indicates plants that occupied more than $5 \%$ of the plot's area):

grasses: Festuca altissima All., Festuca rubra L., Poa trivialis L., Dactylis glomerata L.;

legumes: Trifolium repens L.;

dicotyledons: Aegopodium podagraria L., Urtica dioica L., Impatiens parviflora DC., Stellaria media (L.) Vill., Aruncus sylvestris, Galeopsis tetrahit L., Lamium album L., Glechoma hederacea L., Circaea lutetiana L., Chelidonium majus L., Ficaria verna Huds., Lamium album L., Asarum europaeum L.

There were 18 species of plants in that plot in total. The plot had the poorest flora of all plots;

The structure of the natural population was as follows: snails aged $1+-43.9 \%$ $(\mathrm{N}=69) ; 2+-37.6 \%(\mathrm{~N}=56) ; 3+$ and above $-18.5 \%(\mathrm{~N}=32)$ in a sample of 157 individuals. 


\section{Results}

\section{The age structure of the populations}

The size of the samples collected on the "source plot" and the "inhabited plot", confirmed that a similar density of Helix pomatia existed on the two plots (157 and 142 specimens, respectively). However, the quantity relations between particular age groups differed in the two populations (Table 1), especially in the youngest $1+$ age group. This applied particularly to the percentage contribution made by the snails aged $1+$, which was smaller by $18.1 \%$ in the whole natural population on the "source plot" than in the sample collected on the "inhabited plot". Consequently, the percentage contribution of the older snail group at the age of $2+$ was $13.7 \%$ higher in the population on the "source plot" and at the age of $3+$ and above it was $4.4 \%$ higher than on the "inhabited plot". By taking into account the presence of marked Roman snails aged $1+$ in the collected samples, it was possible to determine that the disproportion between the contributions of snails in this age group on the "source plot" and the "inhabited plot" decreased from $18.1 \%$ to $14.5 \%$, with practically identical contributions of farmed Roman snails in the age groups $1+$ on the two plots $(52.7 \%$ and $51.1 \%$, respectively). However, on the "empty plot" a local natural population of Roman snails was practically non-existent. During the collection of the sample, 132 Roman snails of farmed origin were harvested on this plot, which is $43.5 \%$ to $71.4 \%$ more than on the other two research plots, respectively. Marked snails aged $1+$ of farmed origin were found two months after introduction at a distance of $30 \mathrm{~m}$ from the research sites determined in the field.

Table 1. Age structure of the Roman snail (Helix pomatia L.) populations two months after the introduction of the farmed snails aged 1+ (15 July 2011)

\begin{tabular}{|c|c|c|c|c|c|c|c|c|}
\hline \multirow{3}{*}{ Plot } & \multicolumn{8}{|c|}{ Age groups } \\
\hline & \multicolumn{2}{|c|}{$1+$} & \multicolumn{2}{|c|}{$2+$} & \multicolumn{2}{|c|}{$3+$ and above } & \multicolumn{2}{|c|}{ Total } \\
\hline & No & $\%$ & No & $\%$ & No & $\%$ & No & $\%$ \\
\hline \multicolumn{9}{|l|}{ Source plot } \\
\hline Total samples & 146 & 62.4 & 56 & 23.9 & 32 & 13.7 & 234 & 100.0 \\
\hline Farmed snails in total sample & 77 & 32.9 & & & & & & \\
\hline Farmed snails in $1+$ group & & 52.7 & & & & & & \\
\hline Total specimens per $\mathrm{m}^{-2}$ & 0.15 & & 0.06 & & 0.03 & & 0.23 & \\
\hline Natural specimens per $\mathrm{m}^{-2}$ & 0.07 & & 0.06 & & 0.03 & & 0.16 & \\
\hline Farmed specimens per $\mathrm{m}^{-2}$ & 0.08 & & & & & & & \\
\hline \multicolumn{9}{|l|}{ Inhabited plot } \\
\hline Total samples & 180 & 76.9 & 34 & 14.5 & 20 & 8.6 & 234 & 100.0 \\
\hline Farmed snails in total sample & 92 & 39.8 & & & & & & \\
\hline Farmed snails in $1+$ group & & 51.1 & & & & & & \\
\hline Natural specimens per $\mathrm{m}^{-2}$ & 0.09 & & 0.03 & & 0.02 & & 0.14 & \\
\hline Farmed specimens per $\mathrm{m}^{-2}$ & 0.09 & & & & & & & \\
\hline Total specimen per $\mathrm{m}^{-2}$ & 0.18 & & 0.03 & & 0.02 & & 0.23 & \\
\hline \multicolumn{9}{|l|}{ Empty plot } \\
\hline Farmed snails & 132 & 100.0 & & & & & 132 & 100.0 \\
\hline Farmed specimens per $\mathrm{m}^{-2}$ & 0.13 & & & & & & 0.13 & \\
\hline
\end{tabular}




\section{Shell diameter}

Snails aged 1+ from the natural population inhabiting the "source plot" $(\mathrm{N}=65)$ had on average a larger shell diameter than the snails in the natural population on the "inhabited plot" $(\mathrm{N}=88)$ with a highly significant difference (t-test, $\mathrm{t}=-3.04$, $\left.\mathrm{DF}=138, \mathrm{P}=1.09^{-5}\right)$ (Figure 1). However, in the older age groups: " $2+$ " $(\mathrm{N}=56$ and $\mathrm{N}=34$, respectively) or " $3+$ and above" $(\mathrm{N}=32$ and $\mathrm{N}=20$, respectively) such statistically significant differences were not established $(\mathrm{t}=1.26, \mathrm{DF}=78, \mathrm{P}=0.21$, and $\mathrm{t}=1.58 ; \mathrm{DF}=48.1 ; \mathrm{P}=0.12$, respectively). To take into account the contribution of farmed Helix pomatia aged 1+, which were introduced into the individual plots two months earlier, to the investigated natural populations inhabiting the plots, six samples of snails from the age group were collected for comparison, including snails from the greenhouse (Figure 2). These snails had been measured in May at the moment of transfer, before they were introduced into particular experimental plots. In July, two months after their introduction, it was established that farmed snails aged $1+$ on the "source plot" $(\mathrm{N}=65)$ had a significantly smaller shell diameter (t-test, $\mathrm{t}=2.02 ; \mathrm{DF}=124.4 ; \mathrm{P}=0.045)$ than the snails from the natural population $(\mathrm{N}=75)$. However, on the "inhabited plot" statistically significant differences between the two groups $(\mathrm{N}=88$ and $\mathrm{N}=92$, respectively) were not detected ( $\mathrm{t}$-test, $\mathrm{t}=1.15$; $\mathrm{DF}=177.8 ; \mathrm{P}=0.25)$. Despite that, the snails of farmed origin in the "source plot" $(\mathrm{N}=75)$ had a significantly larger shell diameter $\left(\mathrm{t}\right.$-test, $\left.\mathrm{t}=2.80 ; \mathrm{DF}=161.9 ; \mathrm{P}=5.3^{-3}\right)$ than two months earlier when they were still in the greenhouse $(\mathrm{N}=299)$. However, the snails of farmed origin on the "empty plot" $(\mathrm{N}=127)$, devoid of a local natural population grew more quickly than on the "source plot" $(\mathrm{N}=75)$ and on the "source plot" they grew more quickly than on the "inhabited plot" $(\mathrm{N}=92)(\mathrm{LSD}$-test, $\mathrm{F}=62.3$; D.F $=293 ; \mathrm{P}=0.00$; Cochran's test: $\mathrm{c}=0.38 ; \mathrm{P}=0.41)$. The increase in the shell diameter of the farmed snails on the "inhabited plot" $(\mathrm{N}=92)$ was not established statistically in the two-month period of study compared to the sample of these snails harvested from the greenhouse in May $(\mathrm{N}=299)$ ( $\mathrm{t}$-test, $\mathrm{t}=-1.41 ; \mathrm{DF}=176.9$; $\mathrm{P}=0.16)$. On this plot farmed snails derived from reproductive adults from the "source plot" were introduced into the area occupied by another population and they 'adjusted' their size to the specimens aged 1+ belonging to this population. In this context, attention should be paid to the greater cumulative density of snails aged $1+$ in the population from the "inhabited plot". Snails from the different age groups showed considerable variation in shell diameter, which was already evident in specimens aged $1+$ in the greenhouse and in the same, marked specimens derived from Roman snail samples harvested two months later in natural plots (Figures 2 and 4). This is why, as mentioned above, the estimation of their age based exclusively on shell diameter was not reliable.

\section{Body weight}

As may have been expected from the shell diameters, snails aged $1+$ in the natural population settled on the "source plot" $(\mathrm{N}=65)$ had on average a greater body weight than snails from the natural population on the "inhabited plot" $(\mathrm{N}=88)$ and there was a highly significant statistical difference (t-test: $\mathrm{t}=4.64$; $\mathrm{DF}=127.6$; $\left.\mathrm{P}=7.5^{-6}\right)$. Likewise, no statistically significant differences in the older age groups, " $2+$ " 
( $\mathrm{N}=56$ and $\mathrm{N}=34$, respectively) or " $3+$ and above" $(\mathrm{N}=32$ and $\mathrm{N}=20$, respectively) were established $(\mathrm{t}=-1.66 ; \mathrm{DF}=81.9 ; \mathrm{P}=0.1$; and $\mathrm{t}=-0.85 ; \mathrm{DF}=50.0 ; \mathrm{P}$ $=0.4$, respectively) (Figure 3 ). In July, two months after the introduction of farmed snails to the natural populations on the "source plot" and the "inhabited plot" (Fig. 4), statistically significant differences between the average values of the body weight of snails aged $1+$ from the farm and those from the natural population were not found $(\mathrm{N}=75$ and $\mathrm{N}=65$, and $\mathrm{N}=92$ and $\mathrm{N}=88$, respectively) $(\mathrm{t}=-1.59 ; \mathrm{DF}=129.5 ; \mathrm{P}$ $=0.15$; and $\mathrm{t}=0.17 ; \mathrm{DF}=177.4 ; \mathrm{P}=0.86$, respectively). No statistically significant growth was found in the body weight of farmed snails on the "source plot" $(\mathrm{N}=75)$ since their transfer from the greenhouse to the natural population, compared to the sample of snails from the greenhouse $(\mathrm{N}=299)(\mathrm{t}=1.56 ; \mathrm{DF}=129.9 ; \mathrm{P}=0.12)$.

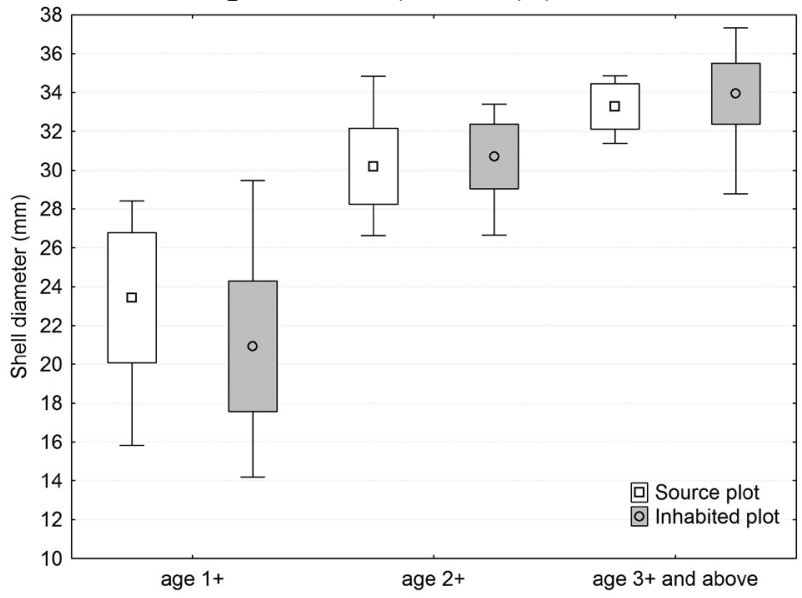

Box represents \pm standard deviation (SD) around mean; whiskers indicate maximum and minimum value.

Figure 1. Shell diameter in two natural populations of Roman snail (Helix pomatia L.)

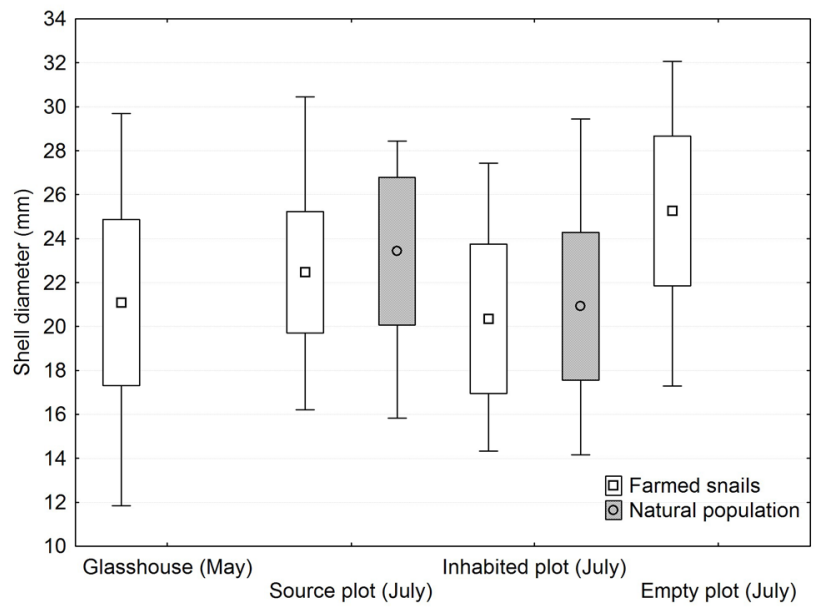

Box represents \pm standard deviation (SD) around mean; whiskers indicate maximum and minimum value.

Figure 2. Shell diameter of Roman snail (Helix pomatia L.) at $1+$ age 


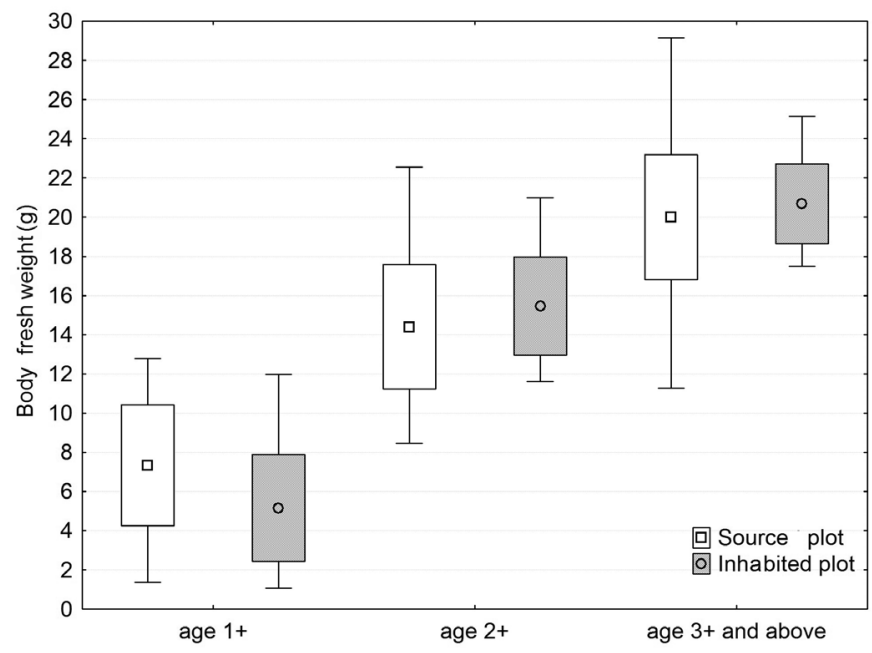

Box represents \pm standard deviation (SD) around mean; whiskers indicate maximum and minimum value.

Figure 3. Body fresh weight in two natural populations of Roman snail (Helix pomatia L.)

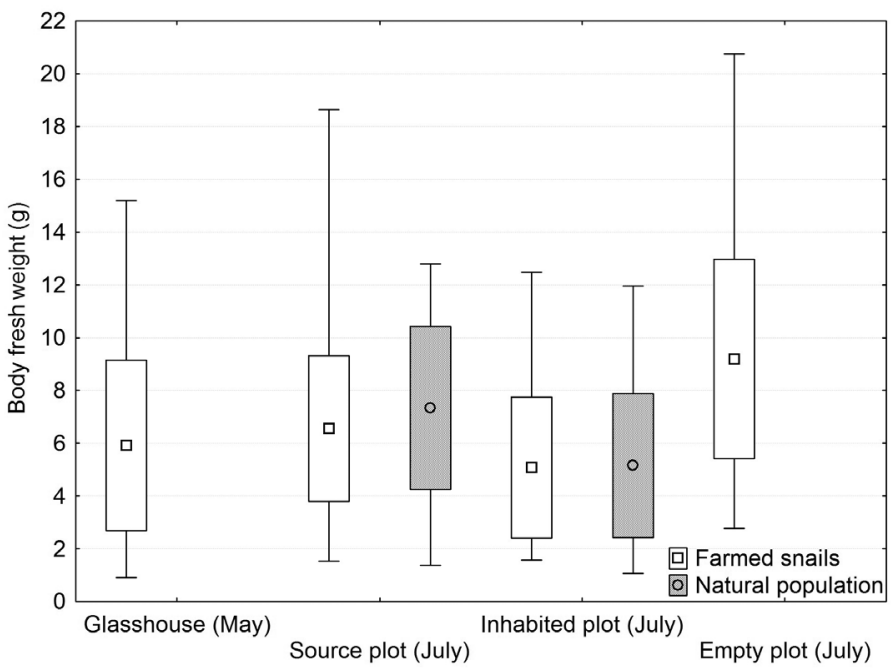

Box represents \pm standard deviation (SD) around mean; whiskers indicate maximum and minimum value.

Figure 4. Body fresh weight of Roman snail (Helix pomatia L.) at $1+$ age

However, the snails of farmed origin on the "empty plot" $(\mathrm{N}=127)$, devoid of a local natural population increased in two months by $55.9 \%$, more quickly than on the "source plot" $(\mathrm{N}=75)$ and on the "source plot" $(\mathrm{N}=75)$ more quickly than on the "inhabited plot" $(\mathrm{N}=92)$ (LSD-test: $\mathrm{F}=45.83 ; \mathrm{DF}=293 ; \mathrm{P}=0.00$; Cochran's test: $\left.\mathrm{c}=0.49 ; \mathrm{P}=1.76^{-4}\right)$. 
At the same time, however, the body weight of farmed snails on the "inhabited plot" $(\mathrm{N}=92)$ decreased significantly compared to the sample of greenhouse snails $(\mathrm{N}=299)$ measured in May $(\mathrm{t}=-2.27 ; \mathrm{DF}=179.6 ; \mathrm{P}=0.02)$.

\section{Discussion}

It was found that the experimental introduction of the snails at the age of $1+$, bred and raised under farm conditions, to the natural environment had a clear positive influence on natural or naturalized populations within the area of the research plots with regard to the following interpretation of the results:

- the attempt to create a naturalized population on the specially prepared "empty plot" that had no native natural population was successful. The farmed Roman snail grew most quickly on this meadow plot compared to the other two plots because it was sown with fodder vegetation, in particular the Roman snail's favourite white clover (Trifolium repens) and related species. An important role was also played by the establishment of hiding places for snails in the form of heaps from calcareous stones,

- farmed snails also undertook seasonal migrations, characteristic of the Roman snail, thus increasing their territorial range 9- to 10-fold within two months. The migrations were especially intensive by snails from the naturalized population on the meadow "empty plot",

- slower growth than on the "empty plot" was shown by farmed snails on the park "source plot" from which their native population originated, with access to suitable herbaceous plants such as nettle (Urtica dioica L.), and slowest growth on half-forest, natural "inhabited plot" occupied by a foreign population. There were statistically highly significant differences $(\mathrm{P}<0.01)$ with regard to the shell diameter and body weight,

- on both plots with natural populations of Roman snail, the growth rate of farmed snails aged 1+ model was approximated to the model of growth rate of the same group aged $1+$ within these populations,

- the lack of statistically significant differences between shell diameters and body weight of snails aged $1+$ from both natural populations pointed to the close genetic relationship of the two populations rather than the lack of differences in trophic and microclimatic conditions between the "source plot" and the "inhabited plot",

- the active protection of Roman snails using farmed snails aged $1+$ is justified mainly on meadow plots that have no natural populations and are sown with a species-rich mixture of fodder and meadow plants, with co-dominance of Brassica rapa $\times$ Brassica rapa subsp. chinensis, white clover (Trifolium repens L.), but also Medicago $\times$ varia Martyn, Trifolium repens L., Trifolium pratense L., and Trifolium incarnatum. It is recommended that the introduced snails have access to calcareous rock debris and soil formed over calcareous bedrock.

The above interpretation of the results is confirmed by the literature. Namely, the

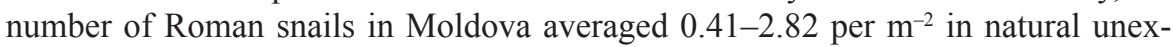




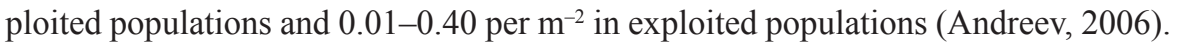
In Lithuania, the density of unexploited populations in national parks and old cemeteries averaged 1.15-2.16 per $\mathrm{m}^{-2}$ (Klimas et al., 2012). Therefore, based on the literature data cited above, the natural Polish populations from the "source plot" and the "inhabited plot" with a stocking density of $0.14-0.16$ per $\mathrm{m}^{-2}$ should be considered highly exploited. The introduction of farmed snails aged 1+ into these plots increased the population by around $40 \%$ to 0.23 per $\mathrm{m}^{-2}$. It is permissible to assume that this effect was actually greater, because, unlike adult specimens, it was not easy to find relatively small snails aged $1+$ in thick grass and thickets. What is more, the introduced year $1+$ snails were found to naturally migrate, because, as mentioned previously, during the sampling two months after the introduction, they were found 30 metres away from the limits of research plots. This means that the farmed snails aged $1+$ expanded their territory even 9 -fold over 2 months. This phenomenon was especially noticeable on the "empty plot" where particularly beneficial trophic conditions were created for the snails by sowing their favourite fodder plants, which will be discussed below. That is why it is to be expected that this migration is seasonal and the snails will return to the site, for example during the reproductive period. Such natural migration and return movements were investigated by Lind (1990), who made observations of marked Roman snails in their own natural habitats. The age structure of the population of Roman snails after the introduction of the farmed Roman snails aged 1+ varied depending on habitat type and the presence of a natural population.

Consideration must be given to the fact that one year earlier 4,000 mature Helix pomatia were removed from the natural population inhabiting the area surrounding the "source plot" in Balice, in spring 2010, in order to obtain farmed hatchlings under greenhouse conditions. On this more exploited plot the total proportion of the older snails aged $2+$ plus $3+$ and above reached $61 \%$ compared to only $38 \%$ on the "inhabited plot". Similarly, Andreev (2006) observed that the proportion of adult Roman snails in Moldova was greater in exploited populations than in less exploited ones. It follows that the removed mature adults did not have the opportunity to reproduce in natural conditions, which could be the reason for the relative shortage of the youngest age group of Roman snails in the collected sample. Therefore, despite the conducive natural conditions of the plot for the reproduction and development of young Helix pomatia snails, the percentage contribution of snails aged $1+$ hatched in 2010 , in the structure of the natural population was lower by $18.1 \%$ compared to the "inhabited plot" in Mydlniki.

Taking into account the total number of specimens on the two plots resulting from the density of the populations it was actually $21.6 \%$ lower than on the "inhabited plot". However, in July 2011 it was found that the contribution of snails in the older age groups $(2+$ to $3+$ and $>3+)$ to the structure of the exploited population on the "source plot" was nevertheless higher than on the "inhabited plot" by a total of $18.1 \%$ and actually by $63 \%$ if the density of specimens is taken into account.

According to earlier Polish research, which described the natural populations of Helix pomatia from other areas, there could be various causes for these differences. According to the interpretation of Łomnicki (1971) the "source plot" could have be- 
come an 'empty plot' for the older age groups of Helix pomatia in 2010, "where there are favourable conditions for habitation, but for some reasons it was not inhabited." It would indicate simultaneously "greater mobility" of the snails from the neighbouring areas, "which can be explained by the lack of partners for copulation" (Woyciechowski, 1980) in the area further from the researched plot. It is apparent that the research population on the "source plot" was quickly regenerated, despite originally having a low density of snails because of the intensive exploitation in 2010. This regeneration could have been hastened by the favourable habitat conditions for Helix pomatia on the site and by the destabilization of the neighbouring populations from the areas of less favourable conditions, which may have caused more intensive migration of the older snails to the "source plot". Additionally, the regeneration of this population should benefit from the introduction of farmed Helix pomatia aged 1+, the presence of which after 2 months of their introduction to the natural environment, is clearly visible if considering the samples collected from all experimental plots. The number of snails of this origin was greater than $50 \%$ in the $1+$ age group in the populations on the "source plot" and the "inhabited plot". Another issue, or even a threat to the local population on the "inhabited plot" could be the introduction of snails raised from the foreign population in the "source plot" which was undertaken within the scope of this research. Woyciechowski and Lomnicki (1977) observed in the field experiments on mature and appropriately marked specimens that, within mixed natural populations, the reproduction efficiency decreases due to a reduction in the number of observed copulations. Despite that, these authors did not find a reproduction separation between specimens from the various populations. Another issue was the very successful introduction of the farmed hatchlings aged 1+, quoting once again from Łomnicki (1971), into an authentically "empty plot where there are favourable habitat conditions, but for some reason it was not inhabited". This applies to the artificially adapted field site for Helix pomatia on the "empty plot" in Będkowice, where the biotope was not originally favourable for this species of snail because of the domination of xerothermic vegetation and the lack of natural hiding places. In future, the fate of this naturalized population will depend on the renewal of horticultural or agricultural use for the land.

According to the literature, white clover is a favourite food plant for the Roman snail (Klimas et al., 2012) and the growth rate of young Roman snails may depend on the quality of its leaves, which is related to the atmospheric concentration of carbon dioxide (Ledergerber et al., 1998). Irrespective of these literature data, however, most of the investigated snails were observed to feed largely on the annual hybrid plant Brassica rapa $\times$ Brassica rapa subsp. chinensis, which was sown in this plot and is often used in Poland in field farming of the edible brown snail (Helix aspersa). The next favourable plot was the "source plot" in Balice, whereas the worst conditions were on the "inhabited plot" in Mydlniki. Accordingly, the rate of growth of Helix pomatia aged $1+$ decreased for both the natural population and the introduced population of farm origin. This statement emphasizes the fact that the differences in body weight and the shell diameter on the three research plots for the introduced farmed Helix pomatia were highly significant. Polish authors (Woyciechowski and Łomnicki, 1977; Łomnicki, 1971; Woyciechowski, 1980) suggest that Helix pomatia 
from a foreign population do less well after their introduction into a new area inhabited by a local population. However, the farmed Helix pomatia aged $1+$ bred from the breeding adults from the "source plot", reintroduced into the native population, had, after 2 months, a significantly smaller shell diameter compared to the specimens in the natural population.

In conclusion, the two-month observations in the May-June season, which under Poland's natural microclimatic conditions covered the most intensive stage of Roman snail growth, were sufficient to conclude about the high effectiveness of introducing farmed snails aged 1+ into the natural environment: the growth of the farmed Roman snail hatchlings aged 1+ introduced on natural plots was in accordance with species biology and the introduction had an essential, profitable impact on the structure and numbers of the Roman snail in local natural or naturalized populations.

The observations will be continued next year, when marked snails of farmed origin will reach somatic and reproductive maturity at the age of $2+$.

\section{References}

A $\mathrm{ndr}$ e e v N. (2006). Assessment of the status of wild populations of land snail (escargot) Helix pomatia L. in Moldova: the effect of exploitation. Biodivers. Conserv., 15: 2957-2970.

K $1 \mathrm{im}$ a s R., K $1 \mathrm{i}$ m i e n è A., B i e $1 \mathrm{~s} \mathrm{k}$ is T. (2012). The peculiarities of prevalence of Helix pomatia snails in Kurtuvènai Regional Rark (Lithuania). Acta Biol. Univ. Daugavp., 12: 63-68.

Le d e r g e r b e r S., L e a d l e y P.W., S t ö c k li in J., B a u r B. (1998). Feeding behaviour of juvenile snails (Helix pomatia) to four plant species grown at elevated atmospheric $\mathrm{CO}_{2}$. Acta Oecol., 19: 89-95.

Ligaszewski M., Łysak A., W ęg 1 arzy K. (2005). Comparison of the growth rate and body condition of hatchlings of edible snails: Helix aspersa and Roman snails (Helix pomatia) (in Polish). Rocz. Nauk. Zoot., 32: 47-54.

Ligas zewski M., Łysak A., Mach-Paluszkiewicz Z. (2007). Reproductive performance of Helix pomatia (Gastropoda: Pulmonata: Helicidae) and survival of its hatchlings under farm conditions. Am. Malacol. Bull., 22: 1-6.

L i g a s ze w sk i M., S u ró w k a K., S t e k la J. (2009). The shell features of Cornu aspersum (synonym Helix aspersa) and Helix pomatia: Characteristics and comparison. Am. Malacol. Bull., 27: $1-9$.

L in d H. (1990). Strategies of spatial behaviour in Helix pomatia. Ethology, 86: 1-18.

$Ł$ o m n i c k i A. (1971). The structure and regulation of the size of the population of Roman snails, Helix pomatia L., and some issues regarding its protection. Institute of the Conservation of Nature of the Polish Academy of Sciences, Conservation of Nature, 36: 189-255.

Pollard E. (1973). Growth classes in the adult Roman snail (Helix pomatia L.). Oecologia, 12: 209-2012.

Woyciechowski M., Łomnicki A. (1977). Mating frequencies between resident and added individuals in a population of land snail Helix pomatia L. B. Acad. Pol. Sci. Biol., Cl. II, XXV: $159-162$.

Wo y c i e c h ow sk i M. (1980). Experimental studies of the exploitation and overcrowding of a natural population of the Roman snail, Helix pomatia L. Ekol. Pol. - Pol. J. Ecol., 28: 401-421.

$\mathrm{Z}$ a j ą c K. (2008). Monitoring of the number of Roman snails in the Małopolska Voivodeship between 2001-2007. Proc. Symp.: Protection of the population of Roman snails in Poland with regard to their economic application. Opalenica, Poland, 24-25.09.2008, pp. 5-12. 